\title{
Концепция болезни как ценности в романах Идиот Федора Достоевского и Волшебная гора Томаса Манна
}

\author{
The conception of illness as a value in the novels The Idiot \\ by Fyodor Dostoyevsky and The Magic Mountain \\ by Thomas Mann
}

\begin{abstract}
The article is an attempt to analyse the novels The Idiot by Fyodor Dostoyevsky and The Magic Mountain by Thomas Mann in the context of the category of illness. The author undertakes a comparison of the characters suffering from turberculosis: Hans Castorp and Ippolit Terentyev. It is claimed that in both of the works illness acquires the status of a value and opens before the characters a path to self-knowledge. However, while Castorp's illness develops in comfortable conditions and he finally decides to cease his fascination with death, for the terminally ill Terentyev it is far too late to fight for his life. For this reason, the sacralisation of death is alien to Dostoyevsky's character. In his case, death can be perceived as the Lacanian Real that interrupts the self-narrative. The noted phenomenon can be attributed to Dostoevsky's maximalism that urges the Russian novelist to bring the disease to the limits, and take it out of control. Mann, in turn, portrays the disease as a kind of safety valve, keeping the fascination with the dark sides of life in a healthy framework.
\end{abstract}

Keywords: Fyodor Dostoyevsky, Thomas Mann, Idiot, Magic Mountain, illness

Anna Stryjakowska, Uniwersytet im. Adama Mickiewicza w Poznaniu, Poznań - Polska, a.stryjakowska@gmail.com, ORCID ID: https://orcid.org/0000-0001-9429-2849

Предметом рассмотрения в настоящей статье являются избранные аспекты восприятия явления болезни как ценности в романах Идиот (1868-1869) Федора Достоевского и Волшебная гора (Der Zauberberg, 1924) Томаса Манна. В качестве исходной точки рассуждений стоит привести слова Лодовико Сеттембрини - героя романа Волшебная гора, сторонника рационализма и светского гуманизма. Итальянец, разговаривая с протагонистом, высказывается на тему болезни следующим образом:

Болезнь отнюдь не аристократична, отнюдь не почтенна, самый этот взгляд есть болезнь или ведет к ней. [...] Зарубите себе на носу: в болезни отнюдь нет ничего возвышенного, ничего столь почтенного, чтобы она никак не могла сочетаться с глупостью; 
напротив, болезнь скорее - унижение, да, и она очень мучительна, очень оскорбительна, она унижает идею человека... Можно в отдельных случаях относиться к болезни бережно, с сочувствием, но уважать ее как особую духовную ценность - нельзя, это заблуждение, - зарубите себе на носу, - и оно служит началом всех умственных заблуждений (Mann 1959).

Вышеприведенную трактовку болезни, как можно предполагать, трезвую и разумную, разделяет Сьюзен Зонтаг. Американская писательница в эссе Болезнь как метафора (Illness as Metaphor, 1978) разоблачает культурные мифы, сопровождающие туберкулез и рак, советуя читателям, в качестве наиболее здорового подхода, отказаться от метафоризации болезни (Sontag 5). Томас Манн же придерживался другого мнения, воспринимая болезнь как потенциальную ценность, открывающую перед личностью новые возможности в области самопознания. Данный способ мышления связывает автора Будденброоков с идеями Федора Достоевского. В эссе Достоевский - но в меру (Dostojewski mit Maßen, 1946) немецкий классик признает, что Достоевский и Фридрих Ницше, как демонические, больные, одержимые гении, повлияли на его творческий путь не в меньшей степени, чем Гете и Толстой (Mann 2000: 220-221). Манн почтенно относится к болезни самого Достоевского как существенному фактору его таланта. Медицинский взгляд на болезнь как на падение жизненных сил является для немецкого писателя недостаточным и односторонним. В культурном ракурсе болезнь может, по его мнению, восприниматься как подъем, интенсификация жизни; она становится в данном контексте даже условием познания и духовного роста. Следует, однако, подчеркнуть, что Манн считает болезнь более плодотворной чем здоровье лишь в случае выдающихся личностей. Именно созидательную, порождающую творчество болезнь, считает Манн более ценной для жизни, чем банальное, вялотекущее здоровье (Mann 2000: 230). Обращаясь к Запискам из подполья (1864), писатель акцентирует познавательное измерение страдания, считая темную сторону человека достойным внимания источником истины (Mann 2000: 236).

Литературным воплощением приведенной концепции болезни является роман Волшебная гора, изданный в 1924 году. Художественную и интеллектуальную близость данного романа с творчеством Достоевского отмечает известный русский достоевсковед Георгий Фридлендер, сопоставляющий творческие пути обоих классиков мировой литературы (Fridlender 1977). Фридлендер, однако, исследует вопрос в довольно широком контексте, уделяя детальное внимание в основном сходству романов Бесы (1871-1872) и Доктор Фаустус (Doktor Faustus, 1947) (Fridlender 1997). Попытки подробного сравнительного анализа произведений Идиот и Волшебная гора пока не предпринимались. Правда, Владислав Пронин, автор учебного по- 
собия по немецкой литературе, отмечает реминисценции из романа Идиот в Волшебной горе, но ограничивается лишь лаконичными замечаниями про сходство князя Мышкина и Ганса Касторпа, а также Настасьи Филипповны и Клавдии Шоша (Pronin 285). Желая частично восполнить данный пробел, попытаюсь сравнить некоторые аспекты художественной трактовки категории болезни в обоих произведениях, сосредоточившись на героях, больных туберкулезом - Гансе Касторпе и Ипполите Терентьеве и начав с Касторпа как более сложного и зрелого персонажа.

Волшебная гора - это роман-воспитание о формировании личности молодого инженера Ганса Касторпа, очарованного декадентской атмосферой швейцарского санатория для больных туберкулезом. Герой приезжает в Давос к двоюродному брату, но, узнав, что он сам болен, остается в санатории на семь лет. По словам Зонтаг, несмотря на то, что Волшебная гора является поздним, сознательным комментарием к мифу о туберкулезе, роман этот миф репродуцирует, изображая болезнь как фактор, обогащающий героя, расширяющий его ментальную жизнь (Sontag 36). Действительно, болезнь дает герою возможность приостановить стандартную мещанскую жизнь „внизу”, вводит его в состояние внутреннего напряжения, волнения и интроспекции. Интеллектуальная обстановка санатория позволяет молодому мужчине исследовать до сих пор вытесняемые, „темные” стороны своей личности, изучать и удовлетворять желания, неуместные в его обычной жизни, тестировать различные мировоззрения. В последнем его наставниками становятся герои-носители идей, главным образом упомянутый Сеттембрини, либерал и гуманист, и иезуит Нафта, культивирующий мистическое страдание. Сеттембрини в целом поощряет эксперименты Касторпа, определяя экзистенциальную ситуацию героя латинским выражением ,placet experiri” („стоит пробовать”).

Ганс явно увлечен описанными преимуществами болезни, он охотно остается на горе, и даже развивает в себе почтение смерти, приходя к выводу, что процесс умирания наделяет человека достоинством. Стоит здесь упомянуть точку зрения неизлечимо больного пациента, господина Альбина, который думает о совершении самоубийства. Осознание близкой смерти вызывает у героя ощущение безграничной свободы, что отсылает к идее вседозволенности, творчески разрабатываемой Достоевским. Слова господина Альбина возбуждают Ганса, открывая перед ним возможности наслаждения позором болезни:

[...] если честь имеет немалые преимущества, то их имеет, и позор, и тогда они, пожалуй, даже необъятнее. А когда он, для пробы, перенесся в положение господина Альбина и постарался представить себе, что будет, если совсем освободиться от бремени чести и вкушать лишь бездонные преимущества позора, то на миг с испугом ощутил неистовое блаженство, которое заставило его сердце биться еще торопливее (Mann 1959). 
Легко влившись в микрокосм санатория, герой начинает пренебрегать жизнью внизу, считая людей из своей социальной сферы холодными, пошлыми и жестокими. Ганс до той степени интернализирует этот своеобразный аристократизм, что ему кажется, что пренебрежение накопительством, цинизмом и даже возвышающее влечение к болезни сопровождали его уже перед приездом на гору:

Видите ли, нужно, вероятно, быть по натуре довольно толстокожим, чтобы так вот, безоговорочно мириться с воззрениями людей там, на равнине, с их вопросами вроде: „А разве у него еще есть деньги?” - и с выражением их лиц, когда они говорят такие вещи. Мне это и раньше казалось чем-то неестественным, хотя я даже не homo humanus, а теперь мне ясно, что всегда поражался этому. Может быть, в таком неприятии сыграло роль скрытое предрасположение к болезни [...] (Mann 1959).

В приведенном контексте обращает на себя внимание символика пространства, совпадающая с традиционными воображениями человечества: гора становится пристанищем для личностей утонченных, чувствительных, привлекательных, в то время как на низинах (т. е. в пространстве обычной жизни) обитают люди узкого кругозора, мелкие в интеллектуальном и эмоциональном плане.

Существенным элементом пристрастия Касторпа к болезни является его увлечение русской пациенткой Клавдией Шоша. Мадам Шоша можно считать femme fatale, она ассоциируется с ноншалантностью, свободой нравов, хаосом, страстью. Ганс, изначально раздраженный свободным поведением Клавдии, быстро влюбляется в женщину. Данное чувство для него настолько неожиданно, что он сначала не способен найти адекватные слова для его описания и долгое время не решается явно ухаживать за обаятельной героиней. Увлечение больной, небрежной, во многом отличающейся от него женщиной герой считает приключением вне правил разума, но вскоре он признает, что настоящая любовь - не что иное, как безумие, абсурд и запретный плод. Стоит заметить, что любовь в романе иногда отождествляется с болезнью, что вписывается в приведенные Зонтаг соображения о туберкулезе как проявлении именно любви, страсти и подавленных эмоций. Данного взгляда придерживается доктор Кроковски, врач санатория, полагающий, что „симптомы болезни - это замаскированная любовная активность, и всякая болезнь - видоизмененная любовь” (Mann 1959). От увлечения Клавдией Ганса предостерегает Сеттембрини, считающий мадам Шоша воплощением отождествляемого с Востоком беспорядка, иррационализма, почтительного отношения к страданию и, следовательно, влечения к смерти. Клавдия отчасти подтверждает опасения итальянца, указывая в разговоре с Гансом на достоинства саморазрушения. Слова героини очень близки художественному миру Достоевского: 
Морали? Тебе интересно? Ну вот, мы считаем, что нравственность не в добродетели, то есть не в благоразумии, дисциплинированности, добрых нравах, честности, но скорее в обратном, я хочу сказать - когда мы грешим, когда отдаемся опасности, тому, что нам вредно, что пожирает нас. Нам кажется, что нравственнее потерять себя и даже погибнуть, чем себя сберечь. Великие моралисты вовсе не были добродетельными, они были порочными, искушенными в зле, великими грешниками, и они учат нас по-христиански склоняться перед несчастьем... (Mann 1959).

Слова Клавдии о преимуществе саморазрушения Ганс повторяет потом, после смерти слишком бережного по отношению к самому себе Иоахима. В цитируемом же разговоре герой признается мадам Шоша в любви, рассуждая о магическом единстве тела, любви и смерти. Последнюю он называет торжественной и величественной силой, гораздо выше жизни [,,которая хохочет, наживает деньги и набивает брюхо" (Mann 1959)] и прогресса. Герои проводят вместе карнавальную ночь, что Сеттембрини воспринимает как поражение в процессе воспитания молодого человека. Эта трактовка представляется ошибочной - во время пребывания в санатории Ганс ментально взрослеет, приобретает новые знания и умения, дистанцируясь от своих учителей и вырабатывая свое собственное, независимое мировоззрение, которое в конечном счете оказывается жизнеутверждающим. Решающим моментом является в этом отношении пробег на лыжах во время пурги, когда Ганс впервые встречается с осязаемой угрозой собственной смерти. Герою снится тогда знаменательный сон, в котором он сначала наблюдает за счастливыми, разумными и красивыми людьми на Средиземноморье (данное видение похоже на сны героев Достоевского о золотом веке человечества), а затем становится свидетелем ужасной сцены поглощения младенца двумя старыми женщинами. Ошеломленный герой приходит к заключению, что сон отражает его ментальные колебания. Как и люди из сновидения, он познал величие и блаженство смерти, что для него является условием познания и выбора жизни. Герой с этого момента противопоставляет смерти любовь и не позволяет этой первой овладеть его мыслями. Приняв решение, Ганс освобождается из снежной ловушки и возвращается в Берггоф. Как суммирует германист Малгожата Лукасевич, Манн в решающий момент способен высказаться против увлечения смертью и встать на сторону жизни (Łukasiewicz 86). Следует при этом еще раз подчеркнуть, что опыт болезни, саморазрушения и изучения иррациональных, темных сторон личности изображен Манном как необходимое условие познания и утверждения жизни.

В намеченном контексте стоит перейти к рассмотрению романа Идиот Достоевского. Восприятие болезни как ценности свойственно, в первую очередь, князю Льву Мышкину, испытывающему эпилептический экстаз как момент высшей гармонии и связи со сверхъестественным. Вопрос болезни Мышки- 
на рассматривался в научной литературе неоднократно (Bogdanov; Przybysz). В данной статье предлагаю сопоставить Касторпа с Ипполитом Терентьевым, больным, как герой Манна, туберкулезом и склонным подвергать свою болезнь глубокому осмыслению. Ипполита и Ганса связывают некоторые элементы во внешнем виде и поведении, свойственные больным туберкулезом: бледность лица, румянец и горящие глаза, состояние напряжения, чередующиеся припадки смеха и тревоги. Положение Терентьева при этом намного хуже: его болезнь в последней стадии, ему осталось жить лишь несколько недель. Данный факт обуславливает в целом отрицательное отношение Ипполита к смерти и, с моей точки зрения, предопределяет главные различия между героями. Молодых людей объединяет, в свою очередь, порожденное контактом со смертью утверждение жизни и предоставленная болезнью возможность предаться размышлениям, обогащающим интеллект и позволяющим исследовать тайные уголки психики. Ипполит описывает данное состояние в своем Необходимом объяснении. Задумываясь над смыслом жизни, герой, сходным с Гансом образом, начинает пренебрегать людьми здоровыми, погруженными в суету, считая их злыми и несчастливыми, лишенными способности радоваться жизни. Он завидует здоровым людям, уверенный в том, что сам не стал бы на их месте растрачивать жизнь, но наслаждался бы ей самой по себе:

\footnotetext{
Пусть тот, кому попадется в руки мое „Объяснение”, и у кого станет терпения прочесть его, сочтет меня за помешанного, или даже за гимназиста, а вернее всего за приговоренного к смерти, которому естественно стало казаться, что все люди, кроме него, слишком жизнью не дорожат, слишком дешево повадились тратить ее, слишком лениво, слишком бессовестно ею пользуются, а стало быть, все до единого не достойны ее! И что же? я объявляю, что читатель мой ошибется, и что убеждение мое совершенно независимо от моего смертного приговора. Спросите, спросите их только, как они все, сплошь до единого, понимают в чем счастье? [...] Дело в жизни, в одной жизни, - в открывании ее, беспрерывном и вечном, а совсем не в открытии! (Dostoevskij 390).
}

Достойно внимания то, что похожую уверенность мы замечаем у Мышкина в разговоре с генеральшей и сестрами Епанчиными. Несмотря на полугодичную прикованность к кровати, Ипполит проявляет интерес к жизни: получает удовольствие от помощи нищему медику, ищет правды и одобрения со стороны других, влюбляется в Аглаю, с неким презрением смотря на нерешительность Мышкина по отношению к барышне.

Со временем желание жить все чаще чередуется, однако, с безразличием, а приближающаяся смерть приводит к решению о самоубийстве как единственном оставшемся проявлении свободной воли. Данный вывод приводит на мысль слова господина Альбина, также решившего в соответствующий момент окончить свою жизнь и посеявшего в Гансе зерно вседозволенности, которая не чужда и Ипполиту. Герой Достоевского рассуждает о возможности 
убийства десяти человек - для Ипполита-убийцы - практически безнаказанного. Следует здесь заметить, что идея вседозволенности выступает у Достоевского в крайних проявлениях, в то время как уравновешенный Манн останавливается все-таки на социально одобряемом удовлетворении влечений.

Ипполит находится в трагическом положении: он не хочет жить на унижающих его условиях, но одновременно боится смерти. Несмотря на то, что юноша замечает некие достоинства болезни, расширяющие сознание и побуждающие к искренности, ему, в отличие от Ганса, чужда сакрализация самой смерти. Он воспринимает ее как орудие всеохватывающей природы, способной беспощадно уничтожить даже высшие существа. О жестокости природы напоминает картина Ганса Гольбейна Мертвый Христос (Der Leichnam Christi im Grabe, 1521-1522) в доме потерявшего веру, инфернального Парфена Семеновича Рогожина. В ней Ипполит увидел отражение беспощадного могущества природы, отнимающего веру в бессмертие:

Тут невольно приходит понятие, что если так ужасна смерть и так сильны законы природы, то как же одолеть их? Как одолеть их, когда не победил их теперь даже тот, который побеждал и природу при жизни своей, которому она подчинялась, которой воскликнул: „Талифа куми”, - и девица встала, „Лазарь, гряди вон”, - и вышел умерший? Природа мерещится при взгляде на эту картину в виде какого-то огромного, неумолимого и немого зверя или, вернее, гораздо вернее сказать, хоть и странно, - в виде какой-нибудь громадной машины новейшего устройства, которая бессмысленно захватила, раздробила и поглотила в себя, глухо и бесчувственно, великое и бесценное существо - такое существо, которое одно стоило всей природы и всех законов ее, всей земли, которая и создавалась-то, может быть, единственно для одного только появления этого существа! Картиной этою как будто именно выражается это понятие о темной, наглой и бессмысленно-вечной силе, которой всё подчинено, и передается вам невольно (Dostoevskij 403-404).

Ужас смерти навещает героя во сне также в виде скорлупчатого насекомого, похожего на скорпиона, которого пытается поглотить собака Норма (результат этой борьбы неизвестен). Достоевсковед Татьяна Касаткина интерпретирует скорпиона как символ осатаневшей души, обращая при этом внимание на присутствие защитника в виде собаки (Kasatkina 680-681). Сон юноши ассоциируется с видением Ганса Касторпа, который, столкнувшись со смертью в виде старух поглощающих младенца, решает в пользу жизни. Но Ипполит уже лишен возможности принимать решения в этой области. Хотя герой допускает существование вечной жизни, эта гипотеза не в состоянии его утешить.

Проведенный анализ произведений двух великих классиков позволяет сделать вывод, что в случае Ипполита смерть проявляется как лакановское Реальное, в интерпретации Агаты Белик-Робсон: как „чистая травма” (Bielik-Robson 227), прерывающая автонарратив личности (Bielik-Robson 217218). На возможность данной интерпретации указывает также неопределен- 
ность твари во сне героя: Реальное ведь не поддается символизации. Его ощущение, однако, предопределяет направление мыслей героя, значительно сужая пространство „placet experiri”. Ганс Касторп же болеет в комфортных, по словам Фридлендера - тепличных (Fridlender 1977), условиях. Смерть функционирует здесь как Символическое, безопасная дистанция позволяет наслаждаться свободным экспериментом. Единственным исключением представляется пурга - знаменателен факт, что именно тогда Ганс выступает против смерти, которая для неизлечимо больного Ипполита давно является чем-то неестественным, нечеловеческим. Читатель вполне вправе относить отмеченный феномен к максимализму Достоевского, который доводит болезнь до пределов, выводит ее из-под контроля. Манн, в свою очередь, изображает болезнь как своего рода вентиль безопасности, удерживая увлечение темными сторонами жизни в разумных рамках.

\section{Библиография}

Bielik-Robson, Agata. „Na pustyni”. Kryptoteologie późnej nowoczesności. Kraków, Universitas, 2008.

Bogdanov, Nikolaj. „Svâŝennaâ bolezn' Knâzâ Myškina - morbus sacer Fedora Dostoevskogo”. Roman F.M. Dostoevskogo „Idiot”: sovremennoe sostoânie izučeniâ. Red. Tat'âna Aleksandrovna Kasatkina. Moskva, Nasledie, 2001.

Dostoevskij, Fedor. Sobranie sočinenij v devâti tomah. T. 4. Idiot. Moskva, AST, 2004.

Fridlender, Georgij. „«Doktor Faustus» Tomasa Manna i «Besy» Dostoevskogo”. Dostoevskij. Materialy i issledovaniâ. T. 14. Red. Nina Fedotovna Budanova, Irina Dmitrievna Âkubovič. Sankt-Peterburg, Nauka, 1997.

Fridlender, Georgij. „Dostoevskij i Tomas Mann”. Izvestiâ Akademii nauk SSSR. Seriâ literatury i âzyka, t. 36, nr 4, 1997. Web. 12.08.2019. http://20v-euro-lit.niv.ru/20v-euro-lit/articles-germaniya/fridlender-dostoevskij-i-tomas-mann.htm.

Kasatkina, Tat'âna. „Primečaniâ”. Fedor Dostoevskij. Sobranie sočinenij v devâti tomah. T. 4. Idiot. Moskva, AST, 2004.

Łukasiewicz, Małgorzata. Jak być artysta. Na przykładzie Thomasa Manna. Warszawa, Towarzystwo „Więź”, 2011.

Mann, Tomas. Sobranie sočinenij v desâti tomah. Tom 3. Volšebnaâ gora. Per. Vera Stanevič. Moskva, Gosudarstvennoe izdatel'stvo hudožestvennoj literatury, 1959. Web. 12.08.2019. http://lib. ru/INPROZ/MANN/zauberg1.txt.

Mann, Tomasz. Dostojewski $-z$ umiarem i inne eseje. Przeł. Jan Błoński. Warszawa, Wydawnictwo Literackie MUZA SA, 2000.

Pronin, Vladislav. Istoriâ nemeckoj literatury. Moskva, Logos, 2007.

Przybysz, Anna Katarzyna. „Próba czytania choroby księcia Myszkina w kluczu koncepcji duchowości ciała Alexandra Lowena”. Choroba - ciało-dusza w literaturze i kulturze. Red. Justyna Tymieniecka-Suchanek. Katowice, Wydawnictwo Uniwersytetu Śląskiego, 2017.

Sontag, Susan. Choroba jako metafora. AIDS i jego metafory. Per. Jarosław Anders. Kraków, Karakter, 2016. 